\title{
Epistemology of the Self in a Pragmatic Mood
}

\author{
Rosa M. Calcaterra
}

\section{OpenEdition \\ Journals}

Electronic version

URL: http://journals.openedition.org/ejpap/930

DOI: 10.4000/ejpap.930

ISSN: 2036-4091

\section{Publisher}

Associazione Pragma

\section{Electronic reference}

Rosa M. Calcaterra, "Epistemology of the Self in a Pragmatic Mood», European Journal of Pragmatism and American Philosophy [Online], II-1 | 2010, Online since 01 July 2010, connection on 07 May 2019. URL : http://journals.openedition.org/ejpap/930 ; DOI : 10.4000/ejpap.930

This text was automatically generated on 7 May 2019.

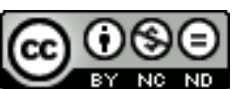

Author retains copyright and grants the European Journal of Pragmatism and American Philosophy right of first publication with the work simultaneously licensed under a Creative Commons AttributionNonCommercial-NoDerivatives 4.0 International License. 


\title{
Epistemology of the Self in a Pragmatic Mood
}

\author{
Rosa M. Calcaterra
}

One of the most characteristic features of classical pragmatism is the opposition to the Cartesian principle of self-transparency, a principle which in fact has been widely criticized also by Marx, Freud and a number of twentieth century's philosophers. Thus, the notion of the authenticity of the self seems nowadays almost unsustainable, and the so called 'dissolution of the subject' - brought about by in the second half of last century might be considered as a corollary of this criticism of Cartesian epistemology of the self. However, a reflection on the notion of authenticity, based on the rich store of critical knowledge now available to us, is perhaps very important in order to clarify the basic structure of that relationship to one's self through which, in concrete experience, one constructs self-understanding and the image of oneself to offer to others. In the following, I address this possibility and show that the overcoming of the Cartesian perspective on the theme of personal identity is not necessarily equivalent to the 'dissolution of the subject.' In this light, I will present a few remarks about contemporary approaches to the epistemology of the self, in order to point out the lively presence of some distinctive features of pragmatism in current philosophical debates on the issue. In particular:

1) The externalist methodology, i.e. the overcoming of introspection as a primary criterion for the access to the so-called 'inner world' and, consequently, the pragmatist restructuring of the conceptual couple inner/outer.

2) The critique of the essentialist notion of the subject/consciousness and the alternative conception of subjectivity as dynamic, plastic, and - finally - a socio-historical reality.

3) The positive emphasis on language as an epistemic dimension, that is, the importance assigned to communicative practices as pivotal activities for every type of knowledge.

4) The interweaving of subjectivity and normativity, namely, the acknowledgment of normativity as a distinctive feature of the human mind. 
2 The theme of subjectivity involves a network of concepts/questions: personal identityself awareness, knowledge of 'other minds' or inter-individual recognition; and numerous conceptual couples that are severely compromised by our long history of ideas: internal/ external, subjective/objective, essence/appearance, mind/language, normative/ descriptive, just to give a few rapid examples. It is a theme that is rarely addressed in the classics of pragmatism, with the exception of James and Mead, ${ }^{1}$ but today it is a particularly urgent subject for reflection, for the well known historical-cultural reasons that affect us closely: globalization, intercultural conflicts, ethical relativism, etc. The theme of subjectivity thus bears witness to the priority of history over philosophy: the 'truth' of the Hegelian assertion according to which philosophy is the activity of leading history to the concept. But, above all, and this is what interests me particularly, it is a theme that - in my opinion - indicates how ephemeral, shifting, if not even - for certain aspects - incongruous, the boundaries are that one tends to erect between different philosophical sectors, in this case between the theoretical-epistemological area of philosophical research and the area of practical philosophy.

In observation I already make use, clearly, of a pragmatist point of view: no dichotomies, and in particular no sharp separation between facts and values, between science and ethics. However, I also make use of Peirce's doctrine about the normative sciences, his theory of the interweaving of logic, ethics and esthetics - keeping in mind that for Peirce, as is well known, the term 'logic' concerns thought in its great complexity and not only the purely 'technical' level of the various forms of reasoning.

4 Based on Peirce's Philosophy and the Conduct of Life (Peirce 1998: 105-22), which is in my opinion preparatory to the famous writing by Peirce on the normative sciences, I have already had the opportunity to indicate that the esthetic level of subjectivity, the socalled affective sphere of the human being, which is usually understood to be heterogeneous to the rational sphere, is instead an integral aspect of it. ${ }^{2}$ In addition, it is necessary - from Peirce's point of view - to include sentiments and subjective emotions among the objects of reflection and reasoning, that is to say, to restore them to the "space of reasons": to that fundamental activity of the human being that consists in giving and asking for justifications for everything that concerns us, thus also for our affective habits and for the consequential behavioral attitudes. This does not mean to minimize the difference between the rational level and the esthetic/affective level, but rather to translate it into an articulated, dynamic and, in a word, public conception of rationality. Such a conception thus includes, as a central aspect, the conviction that sentiments can be said to be 'truly' human precisely in as much as each one of us tends 'normally' to comprehend them and explain them according to an order of sense and of meaning that is inter-subjectively recognizable.

5 According to most interpretations of Philosophy and the Conduct of Life, it exhibits Peirce's support of science rather than of scientism. There is, in fact, a precise delimitation of the effectiveness of scientific research: for Peirce, science is essentially a method of reasoning, the most subtle method for obtaining new information about the objective world, but nevertheless it cannot be considered as the best tool humans can employ in order to solve "vitally important topics." In this very delicate area - Peirce declares - we should rather rely upon instinct and feeling, that is on the most immediate intuitions of human beings. These are rooted in human biology and, thus, are constitutive ingredients of human performance. Nicholas Rescher gives an interesting expression to this point of view: as he says, even though Peirce had always stressed the value of science as a 'social 
process' determined by cognitive and practical interactions, in this paper he intended to show that emotional capacities, i.e. the capacity for love or sympathy, are in reality not less important than the capacity for knowledge. According to Rescher, finally Peirce's suggestion would be that human life is too important to be entrusted to science. ${ }^{3}$

However, it would be incorrect to infer from this suggestion that Peirce is simply maintaining the need to disconnect science and ethics on the basis of the sharp distinction that Hume espoused between reasoning, on one hand, and feelings, on the other. Rather, Peirce's concluding arguments hints at his sinechism, a principle which leaves no room for a substantial contraposition between the accomplishments of rationality and those of feeling.

But there is a major point in Philosophy and the Conduct of Life that challenges the notion, derived from Hume, that there is a substantial difference between science and ethics. As I mentioned earlier, this paradigm appears ruled out by passages emphasizing the cognitive importance of sentiment and hereditary instinct as well as the possibility of an aesthetic dimension in the normative space of rationality. This line of thought is expressed in the context of Peirce's claim that matters of "vital importance" must be left to sentiments and instinct, by the following comment:

There are two conceivable ways in which right sentiment might treat such terrible crises; on the one hand, it might be that while human instincts are not so detailed and emphasized as those of the dumb animals yet they might be sufficient to guide us in the greatest concerns without any aid from reason, while on the other hand, sentiment might act to bring the vital crises under the control of reasoning by rising to such a height of self abnegation as to render the situation insignificant. In point of fact, we observe that a healthy natural human nature does act in both ways. (Peirce 1898: 112-3)

Such a perspective is not in contrast with Peirce's claim that pure scientific research per $s e$ has nothing to do with the criterion of practical utility (Peirce 1898: 107). ${ }^{4}$ In fact, the formerly quoted assertion does not relate to this particular kind of theoretical investigation, but to the impact that rationality, as reflective and 'social' activity, may have on the affective dynamics that normally lead us in our most problematic situations. Consequently, the concluding passage of his discourse points out the positive value of that peculiar sort of human experience we can define as the cognitive experience of feelings, namely a reflective experience on our sentiments and emotions which, by definition, exceeds the pre-logical character of affective dimension. Let me cite this passage at length:

Here we are in this workaday world, little creatures, mere cells in a social organism itself poor and little thing enough, and we must look to see what little and definite task circumstances we have set before our little strength to do. The performance of that task will require us to draw upon that department of the soul which is the most superficial and fallible - I mean our reason -, but upon that department that is deep and sure - which is instinct. Instinct is capable of development and growth - though by a movement which is slow in the proportion in which it is vital; and this development takes place upon lines which are parallel to those of reasoning. And just as reasoning arises from experience, so the development of sentiment arises from the soul's Inward and Outward Experiences (such as meditation, on the one hand, and adversity on the other). Not only is it of the same nature as the development of cognition, but it chiefly takes place through the instrumentality of cognition. The soul's deeper parts can only be reached through its surface .(Peirce 1898: 121-2; my italics)

9 As we have previously seen, cognition is a product of rationality, which, in Peirce's view, is a web of empirical factors and logical norms. However, a crucial aspect of his semiotic 
theory of logic is that rationality's normative aspect essentially consists in the possibility of transferring empirical data to the dimension of logical signs or concepts, namely representations of socially sharable meanings, and, correspondingly, in the possibility of providing theoretic and behavioral attitudes whose justification transcends the dynamics of mere experiential facts, including those bringing about the 'natural' selection and consolidation of some particular human habits. The above quoted assertion that "the development of sentiment arises from the soul's Inward and Outward Experiences" is just an allusion to the normative character of rationality. In any case, what Peirce is pointing out is that even the most deep-rooted human habits are not independent of the regulative power of rational activity. On the contrary, he is confident that philosophy and other sciences "will by low percolation gradually reach the very core of one's being, and will come to influence our lives; and this they will do, not because they involve truths of merely vital importance, but because they are ideal and eternal verities" (ibid.).

To have confidence in such a possibility certainly does not mean proposing once again the ancient parallelism of ethics and philosophical/scientific knowledge. In the paper we are considering, there is indeed a firm rejection of "the Hellenic tendency to mingle Philosophy and Practice." However, in the light of Peirce's remarks about what I defined as cognitive experience of feelings, we may draw the conclusion that he is suggesting an attractive revision of the science/ethics dichotomy deriving from the Humean 'is-ought question.' As I noted earlier, the revision consists in a conceptual strategy that tends to replace the idea that science and ethics belong to different ontological domains with the description of their formal and functional difference. Of course, the statement of a difference is something else than the statement of a dichotomy, as Peirce's stress on the continuum of philosophical-scientific reasoning with the affective sphere demonstrates. And, in my opinion, the intuition that lies behind this argument is compelling. It is concerned, indeed, with the strong evidence that, after all, our sentiments are really 'human' just as far as we are 'normally' inclined to justify the validity of our own esthetical attitudes by means of a capacity that characterizes us as rational beings, i.e. by means of grasping socially shareable horizons of sense and truth.

11 In the following, I intend to offer an indication of the need to follow the pragmatist commitment to going beyond another logical-methodological opposition, namely the dichotomic formulation of the coupled terms inner/external set out by Descartes. At the same time, however, I would like to suggest that it is worthwhile to set aside easy reductionisms, which would lead to losing sight of the complexity of the theme of personal identity. In fact, if on the one hand the wealth of conceptual tools and methodologies perfected by contemporary thought for the elaboration of this theme has greatly increased our possibility to analyze it thoroughly, on the other hand, precisely because of this variety of tools, it is necessary to recognize that a univocal definition of the theme is extremely difficult and improbable.

In a purely schematic way, one can say that one of the most characteristic aspects of the contemporary discussion on the question of self-awareness consists in the challenges made against the dualism between 'internal' and 'external,' 'psychic' or 'mental' and 'physical,' which defines the Cartesian paradigm. As an alternative, a good part of twentieth century thought has tried to carry forward the skepticism expressed by traditional British empiricism towards the ontological-metaphysical vocabulary instituted by Descartes. In this regard favorable reception has been given both to the theories that attempt to dissolve this vocabulary by reducing the entire field of human 
reality to the neuro-cerebral processes, as well as to the theoretical positions that challenge the essentialist and 'centralist' notion of the human subject, pointing to the dimensions of language and of sociality in order to exhibit, instead, its plasticity, its basic relational and dynamic nature: in other words, in order to promote the 'decentralization' of the subject.

The many efforts made to 'dissolve' the Cartesian concept of subjectivity are, however, in conflict with its effective, constant recurrence in our linguistic practices. In any case, the image of the human subject as the autonomous center of experience, knowledge and action continues to be an important point of reference in the formulation of problems that have substantial repercussions at an existential and socio-cultural level. In particular, these are the question of affective dynamics, the question of liberty and of moral or legal responsibility, and more in general, the problem of the definition of the patterns of rationality. In any case, it is a matter of taking into account the ordinary conception that we have of ourselves and of our peers, that is, our usual way of considering ourselves as entities completely different from every other component of the physical-natural world surrounding us. This is a conception within which words such as 'I,' 'subject,' 'consciousness,' 'person,' 'mind' carry out an impressive logical-semantic role of opposition to physicality, in both the ontological and the functional senses.

This scenario appears instead to be seriously disrupted if we turn to areas of discourse and of experience that have made the naturalistic perspective their own, often radicalizing it. This perspective extends from ancient thought to the neurosciences, via British empiricism and Darwinian biology. Since I cannot enter into the detail that would certainly be called for, I will limit myself to noting that in the perspectives developed through Darwinian biology the distinction between internal and external tends to be resolved in favor of exteriority, that is, in terms of an equation mind/brain based on the use of sophisticated technological instruments which allow, as it were, to externalize the mental and describe it like any other physical object.

15 I would like to make a brief comment here on the ambiguity of the option in favor of the descriptive method which characterizes the experimental sciences, a method that in twentieth century philosophy was intended - as we know - to be an alternative to the foundationalist method of traditional thought, and first of all an alternative to its requirements of extra-empirical truths. In a few words, it would be a question of overturning the idea of 'foundation' in favor of that of 'description,' assuming the latter, in principle, to be a sort of antidote to philosophical absolutizations and dogmatisms. However, if one examines the question closely, the invocation of the descriptive method often allows one to glimpse a subtle form of dogmatism. This dogmatism proves to be weaker or stronger according to the degree to which the risks go unnoticed of supporting the ingenuous aspects of scientism, that is to say, the tendency to mistake knowledge based on the analysis of 'empirical facts' for fully founded certainties that are thus consolidated once and for all.

Because of its role as methodological norm both of science and of philosophy, there is a risk that the descriptive method can carry within itself a hidden interweaving among 'description,' 'empirical facts' and 'certainty,' challenging the very meaning of its opposition to the dogmatisms of foundationalist philosophies. This can happen precisely because such a method tends to feed the definitory and essentialist mentality of traditional thought. Wittgenstein's effort to give the descriptive method a clearly antiessentialist statute is particularly important for the theme about which I am speaking, 
just because Wittgenstein tried to show the problematic aspect of the nexus between 'empirical/descriptive' and 'certainty. ${ }^{5}$ In a nutshell, Wittgenstein's thesis is that the very idea of 'certainty' should be removed from the epistemological area and considered, instead, in terms of the so-called "systematic propositions," which constitute the "inherited backdrop" against which the events of our areas of knowledge are played out, but which actually possess a pragmatic foundation and not an empirical justification. ${ }^{6}$ It is, in fact, based on this conceptual strategy that Wittgenstein elaborated his grammatical interpretation of the relationships of internal-external and mind-body. He stated, “"Mental' for me is not a metaphysical, but a logical epithet" (Wittgenstein 1992: 217).

17 I said previously that a good part of twentieth century thought tried to carry forward the skepticism expressed by British empiricism with regard to all the ontologicalmetaphysical vocabulary instituted by Descartes. And I would like now to recall briefly two aspects of David Hume's approach to the theme of personal identity, which have been shown to give a particularly lively contribution to contemporary reflection: (1) the criterion of memory as a basic ingredient of self-knowledge and (2) the socio-biological notion of the human subject. Both criteria are in fact focused on contesting the ontological-metaphysical opposition between 'inner' and 'outer.'

Among the many contemporary variations of Hume's point of view, those which favor the field of language, as a field both of the construction and of the communication of personal identity, are, in my opinion, particularly consistent with pragmatism. The reference here is to the 'narrative' model of personal identity, i.e. a model that tends to show, although in very differing directions, the inextricable interweaving between subjectivity and the socio-cultural environment of which language is the fundamental structure. Thus, for example, in Paul Ricoeur the narrative model aims at recovering in an ethical key some crucial motifs of the traditional notion of a spiritual substance of the human being, whereas in the philosophy of the mind of Daniel C. Dennett (1991) this model is, instead, an integral part of a materialistic reductionism that affects the whole of the Cartesian vocabulary of subjectivity.

According to Dennett, the biological mechanisms of self-protection are the authentic thrust behind the "webs of discourses" that we constantly weave in order to "present ourselves to others and to ourselves"; language is, in itself, a biological function that feeds itself, so that the identity that we attribute to ourselves is in reality the product, not the source of the "narrative sequence," of the "stories we tell others - and ourselves about who we are." From this comes the definition of the self as the "narrative center of gravity," that is, the abstract, nonexistent entity that is postulated for biological and social reasons, and which gives the same advantages that the notion of "gravitational center" has in physics for the calculation of gravitational forces. Here are a few representative passages of Dennett's argumentation:

Our human environment contains not just food and shelter, enemies to fight or flee, and conspecifics with whom to mate, but words, words, words. These words are potent elements of our environment that really incorporate, investigating and extruding them, weaving them like spiderwebs into self-protective strings of narrative. Indeed, when we let in these words, these meme-vehicles, they tend to take over, creating us out of the raw materials they find in our brains.

Our fundamental tactic of self-protection, self-control, and self-definition is not spinning webs or building dams, but telling stories, and more particularly concocting and controlling the story we tell others - and ourselves - about who we are. [...] Our tales are spun, but for the most part we don't spin them; they spin us. Our human consciousness, and our narrative selfhood, is their product, not their 
source.

These strings or streams of narrative issue forth as if from a single source [...]: their effect on any audience is to encourage them to (tray to) posit a unified agent whose words they are: in short, to posit a center of narrative gravity. Physics appreciate the enormous simplification you get when you posit a center of gravity for an object, a single point relative to which all gravitational forces may be calculated. We heterophenomenologists appreciate the enormous simplification you get when you posit a center of narrative gravity for narrative-spinning human body. (Dennett 1991: 417-8)

The biological component of the narrative model of personal identity is quite important in Richard Rorty's point of view, as well. He also gave particular attention to the ethicalsocial aspect of the question, connecting it to the value of solidarity. Here I will limit myself to saying that Rorty maintains that self-knowledge amounts to a process of selfdescription, which sets off a request for recognition on the part of others. To summarize briefly, it is a question of favoring the nexus of language, social interaction and selfawareness, showing that the choice of a certain vocabulary, of a certain way of speaking with oneself and with others, is of a contingent nature, that is, tied to a cultural history that is carried out by means of the gradual acquisition of new metaphors, to which new cognitive and value criteria correspond. We thus touch on the concepts of final vocabulary and of irony, which are two crucial aspects of the 'ethnocentric' point of view that Rorty maintains in various contexts, above all beginning from the 1980s. ${ }^{7}$

Since the final vocabularies do not represent the presumed objectivity of facts, there is no criterion for establishing a priori what the "truest" one is. But this does not mean to negate the importance of a critical recognition of one's own final vocabulary and of some adjustments to it. On the contrary, it is a question of placing the ethical value of communication and of reciprocal knowledge in the foreground, as well as the ethical value of irony, the constructive role that the ironic attitude can carry out in the processes of self-realization and reciprocal recognition, setting this value as the basic condition of the possible changes to a final vocabulary. The following assertions are particularly incisive:

I shall define "ironist" as someone who fulfils three conditions: (1) She has radical and continuing doubts about the final vocabulary she currently uses, because she has been impressed by other vocabularies, vocabularies taken as final by people or books she has encountered; (2) she realizes that argument phrased in her present vocabulary can neither underwrite nor dissolve these doubts; (3) insofar as she philosophizes about her situation, she does not think that her vocabulary is closer to reality than others, that it is in touch with a power not herself. (Rorty 1989: 75)

\section{Moreover:}

For us ironists, nothing can serve as a criticism of a final vocabulary save another such vocabulary; there is no answer to a redescription save a re-re-redescription. Since there is nothing beyond vocabularies which serves as a criterion of choice between them, criticism is a matter of looking on this picture and on that, not of comparing both pictures with the original. Nothing can serve as a criticism of a person save another person, or of a culture save an alternative culture -for persons and cultures are, for us, incarnated vocabularies. So our doubts about our own characters or our own culture can be resolved or assuaged only by enlarging our acquaintance. (Rorty 1989: 82)

I will move towards my conclusion with a reference to the pragmatist conception of sociality as a normative criterion - both epistemic and value-oriented - of central importance. In fact, it is precisely by means of this criterion that classical pragmatism 
tried to oppose the Cartesian principle of self-transparency, a principle which in any case has been nearly cancelled by the criticisms of the notion of the authenticity of the self. As is widely known, Marxian criticism to the ideological superstructure of human reality and psychoanalysis have certainly constituted the most influential passages of these criticisms in all the fields of our culture. However, the return to a reflection on the notion of authenticity, using precisely the rich store of critical knowledge available to us, is perhaps a pathway that we should take in order to attempt to clarify the basic structure of that relationship to one's self through which, in concrete experience, one constructs self-understanding and the image of oneself to offer to others. In order to illustrate this possibility, I will use the analysis made by Charles Larmore, which will help to show that the advisability of going beyond the Cartesian formulation of the theme of personal identity is not necessarily equivalent to the dissolution of the subject. In particular, his analysis will help to show that the level of normativity can be an integral part of an antiessentialist approach to the understanding of the human subject.

The thesis that emerges from the analysis carried out by Larmore (2004) is that "the self relates to itself because it is engaged (s'engage), and because it recognizes itself." The relationship with the self, which is constitutive of the self, is, to put it briefly, essentially practical, a relationship in which nobody else can replace the self and which makes of this self, as a consequence, the self that we alone have to be.

In other words, the structure of the self is normative, because normativity is that which, according to Larmore, constitutes the nature of all mental states - beliefs, desires, emotions, feelings, perceptions ('interpreted' sensations). The essential point of Larmore's proposal is that subjective identity involves the processes of reflection, both cognitive and practical: both those regarding the knowledge of the world and of oneself, and those that consist in taking responsibility for one's beliefs, actions, and affectivity.

It is a thesis that passes, on the one hand, through the examination of the concept of authenticity (in its present meaning of "being fully or purely oneself, that is, behaving in a way according to which the self that we are shows itself without deformations and according to its intrinsic value"), and on the other hand, through the examination of the phenomenon of social mimetism.

One can agree with Larmore that a fruitful recovery of the notion of authenticity presupposes its detachment from the idea that it should be a supreme value, a value that would have to surpass all the others. This is, in fact, a presupposition due to the "philosophical mania" for placing everything in a hierarchical order, whereas, instead, the ethical horizon, or rather, the ethical order has a pluralistic structure, an internal logic according to which a value is no less fundamental or less real if at times one admits the necessity to sacrifice it in order to pursue others. It is necessary to re-examine in this sense the notions of authenticity of the self and of sincerity, but this implies, of course, also going beyond the idea of a pre-existing and pre-ordained structure of the self. The project of authenticity and of sincerity, as opposed to the need to conform to the opinions of others (to what Stendhal calls 'vanity'), is bound to fail precisely because it includes cognitive reflection, which is necessarily tied to the principle of engagement with others: both an 'other' who is real or imaginary, and a Generalized Other, an expression coined by George Herbert Mead to indicate a point of view that can be shared intersubjectively and is thus extended towards universality. In a few words, cognitive reflection "can never reach the point of indifference towards others," which instead is presupposed by Stendhal's project of authenticity. ${ }^{8}$ 
reflection as well as to that of practical reflection, two fields that thus seem inseparable dialectically interwoven in the concreteness of human experience. And it is important to emphasize that to give value to alterity as a leading factor in the ability to reflect and to find 'reasons' to support our knowledge, feelings and behaviors, means also to oppose the consequences implied by the external/internal dichotomy in human relations. Specifically, it means to oppose making this dichotomy concrete in the solipsistic philosophical attitude as well as in the ordinary and strongly rooted conviction that 'true' knowledge in itself is an exclusive prerogative of the subject, that the access to the socalled sphere of the mental or of the so-called 'inner world' is necessarily private, as a matter of fact always precluded from comprehension by others. This is important since under this view each person is destined in the end to an insuperable distance from others in reasoning as well as in desiring and in detesting, in experiencing joy and suffering, in planning and in hoping. Twentieth century philosophy offered numerous conceptual and methodological strategies for putting aside solipsism, strategies which were of course of different sorts (one can think, for example, of the difference between the anti-solipsism of Wittgenstein and that of Husserl). In any case these tools coincide substantially with the assertion by Larmore of the ethical value that the 'public' dimension has in the course of the human subject's cognitive and value-related practices. This is an aspect that runs through all the annotations I have proposed here as a central theme, an aspect that I would like to emphasize with these words by Larmore:

There is no type of exceptional knowledge, either from observation or from inference, which is available only to us, regarding our beliefs or our desires and which would grant an authority to us which nobody else could claim. It is exactly the opposite, and everything that we know about ourselves is founded on the radically public procedures that are observation and inference.

The 'interiority' of the self, if one wants at all costs to preserve the term, does not really mean anything more than the fact that we alone, and nobody else in our place, are able to engage ourselves. [...] To put it briefly, the relationship with oneself that makes each of us a self is neither paradoxical nor mysterious [...], because it is a question of that fundamentally practical relationship, engagement. [...] It is only because in our beliefs and our desires we take positions and we engage 
ourselves to respect their implications that we become objects of knowledge, even

for ourselves. (Larmore 2004: 159-60; my translation from French)

\section{BIBLIOGRAPHY}

CAlCATERRA R. M., (1993), “Wittgenstein e Peirce sull'esperienza interna,” Paradigmi XI, 327-51.

CAlCATERRA R. M., (2003), “Lo spazio normativo dei sentimenti," in Calcaterra R. M., Pragmatismo: i valori dell'esperienza. Letture di Peirce, James e Mead, Roma, Carocci.

Colapietro V., (1989), Peirce's Approach to the Self. A Semiotic Perspective on Human Subjectivity, Albany, SUNY Press.

DE TIENNE A., (2005), “La persona come segno," in Calcaterra R. M. (ed.), Semiotica e fenomenologia del sé, Torino, Aragno.

DENNET D. C., (1991), Consciousness Explained, New York-Boston-London, Little, Brown \&Co.

LARMORE C., (2004), Les pratiques du moi, Paris, Presses Universitaires de France. English translation, (2010), Practices of the Self, Chicago, University Press of Chicago.

PEIRCE C. S., (1898), "Philosophy and the Conduct of Life," in Ketner K. L. (ed.), 1992, Reasoning and the Logic of Things. The Cambridge Conferences of 1898, Cambridge (Ma), Harvard University Press.

RESHER N., (1995), "Peirce on the Validation of Science," in Ketner K. L. (ed.), 1995, Peirce and Contemporary Thought. Philosophical Inquiries, New York, Fordham University Press.

RORTY R., (1989), Contingency, Irony and Solidariety, Cambridge, Cambridge University Press.

RORTY R. \& A. N. BASLEV, (1991), Cultural Otherness. Correspondence with Richard Rorty, London, Indian Institute of Advanced Studies.

WiTTGENSTEIN L., (1969), On Certainty, Oxford, Blackwell.

WitTGENSTEIN L., (1992), Last Writings on the Philosophy of Psychology, vol. II, The Inner and the Outer, 1949-51, Oxford, Blackwell.

\section{NOTES}

1. Important reconstructions of Peirce's conception of subjectivity are Colapietro (1989) and De Tienne (2005: 91-100).

2. I tried to develop this interpretation in Calcaterra 2003.

3. See Resher 1995.

4. Peirce maintains that the true scientific investigator should "stand aloof from all intent to make practical applications," since this intent would not only "obstruct the advance of the pure science" but also would "danger his own moral integrity and that of his readers."

5. Cf. Wittgenstein 1969.

6. A more detailed discussion of this argument can be found in Calcaterra 1993, in which I also compare Wittgenstein's and Peirce's approaches to the relationship inner/outer. 
7. Rorty 1989, especially I and II Part. See also R. Rorty \& A. N. Baslev 1991.

8. Larmore (2004: 40-ss).

\section{AUTHOR}

ROSA M. CALCATERRA

Università Roma Tre

rosamaria.calcaterra[at]uniroma3.it 